\title{
Pediatric Candidates for Temporal Lobe Epilepsy Surgery
}

\author{
Warren T. Blume and Paul A. Hwang
}

\begin{abstract}
Temporal lobectomy is an under-valued and effective therapy for selected children with temporal lobe seizures. This article details three components of the identification and evaluation of such children. The ictal symptoms and signs remains an essential component. This includes an aura suggesting limbic system involvement, and the nature of automatisms and other motor phenomena which may have lateralising value. Electroencephalography continues to accurately identify a principally epileptogenic focus in children and adults. The value of high quality magnetic resonance imaging is emphasized. Invasive studies are required in only a minority of cases. Several studies have revealed that $73-100 \%$ of carefully selected children receive benefit from this procedure whereas significant neurosurgical complications rarely occur.
\end{abstract}

RÉSUMÉ: Candidats à la chirurgie de l'épilepsie temporale chez les patients d'âge pédiatrique. La lobectomie temporale est un traitement sous-estimé et efficace pour certains cas pédiatriques d'épilepsie temporale. Cet article décrit en détail trois volets de l'identification et de l'évaluation de ces enfants. Les symptômes et les signes des crises demeurent un élément essentiel, incluant une aura suggérant une implication du système limbique et la nature des automatismes et des autres phénomènes moteurs qui peuvent être indicatifs de latéralisation. L'électroencéphalographie continue à identifier de façon précise un foyer épileptogène chez les enfants et les adultes. La valeur de l'imagerie par résonance magnétique de haute qualité est soulignée. Des études invasives sont nécessaires chez une minorité de cas. Plusieurs études ont démontré que $73 \%$ à $100 \%$ des enfants choisis avec soin bénéficient de cette chirurgie et que les complications neurochirurgicales majeures sont rares.

Can. J. Neurol. Sci. 2000; 27: Suppl. 1 - S14-S19

Data supporting a sequential clinical and laboratory evaluation of children with possible temporal lobe seizures constitute the initial part of this chapter. Information about the usual medical intractability of temporal lobe seizures and their social consequences follow. Studies on effectiveness of temporal lobectomy in childhood and a step-by-step evaluation protocol conclude the chapter.

\section{Evaluation}

\section{Clinical manifestations of temporal lobe epilepsy in childhood}

Semiology of temporal lobe seizures varies with age of the child as will be seen in the discussion of the several categories of its features.

\section{Aura}

In a video-EEG study of temporal lobe seizures, no specific aura was described among children up to six years of age. ${ }^{1}$ The initial symptoms were simply an arousal reaction such as eye opening. A young child may deny aura but may "look strange" for a few seconds or exhibit fear such as running for a parent. ${ }^{2}$

Blume et $\mathrm{al}^{3}$ found aura in 13 of 14 patients undergoing temporal lobectomy in childhood whose mean age was 8.5 years (range, 2-12 years). Each component suggested limbic system involvement: fear, abdominal, cephalic and experiential phenomena. Aicardi ${ }^{2}$ also describes abdominal sensation and fear as the two most common aurae. Brockhaus and Elger ${ }^{1}$ found aura and psychomotor arrest to be the most common initial symptoms in children ages 7-16 years. Harbord and Manson ${ }^{4}$ found aura in $51(81 \%)$ of 63 children with temporal lobe seizures. Pure abdominal symptoms without other associated aurae or ictal manifestations are exceptional. ${ }^{2}$ Children and

From the London Health Sciences Centre, The University of Western Ontario, Ontario, Canada (W.T.B.) and, Toronto, Ontario, Canada (P.A.H.)

Reprint requests to: Warren T. Blume, London Health Sciences Centre - University Campus, The University of Western Ontario, 339 Windermere Road, London, Ontario, Canada, N6A5A5 
adolescents may describe aurae implicating the limbic system in the same manner as do adults. These include cognitive phenomena such as déja-vu, and psychosensory symptoms such as visual and auditory hallucinations.

\section{Impairment of Consciousness}

Assessment of this is difficult at any age, particularly in younger children. Impaired consciousness may manifest as an arrest of ongoing activity, decreased responsiveness, or a blank stare. However, unresponsiveness may represent dysphasia, apraxia, or pre-occupation with sensory or motor ictal phenomena. $^{5}$

Automatisms, a hallmark of impaired awareness in complex partial seizures, may have expression in young children limited to oro-alimentary movements such as sucking, chewing, searching, swallowing or lip smacking., ${ }^{2,5}$ Gestural automatisms, such as fumbling with objects and picking at clothes, occur infrequently in infants and appear more commonly in children and adolescents. ${ }^{1}$ Blume et $\mathrm{al}^{3}$ found automatisms, including gestural, oro-alimentary, and ambulatory features, in 12 of 14 patients with temporal lobe epilepsy.

Holmes, ${ }^{7}$ in a video-EEG study of complex partial seizures in children, was able to classify the seizures into three types: initial motionless stare followed by automatisms; automatisms at onset; and sudden loss of body tone followed by confusion and automatisms.

\section{Motor Phenomena}

Unilateral tonic contraction, particularly of the face, mouth or upper limb may be seen in seizures of hippocampal origin. ${ }^{2}$ Dystonic posturing of an arm or an arm and a leg in a patient with other features of temporal lobe seizures usually indicates origin in the contralateral temporal lobe. ${ }^{8}$ Automatisms occurring during such dystonia will, therefore, be ipsilateral to origin.

Motor phenomena, versive movements and dystonic posturing were the most frequent manifestations of temporal lobe seizures in preschool children in the study of Brockhaus and Elger. ${ }^{1}$ Such phenomena could be symmetrical tonic or clonic movements or atonic phenomena such as head nodding. The latter can be associated with symmetrical elevation of the arms to resemble infantile spasms. In this study, tonic or clonic movements of the limbs were observed less in older children who often exhibited unilateral motor phenomena, whereas motor phenomena in younger children were primarily symmetrical.

Finally, a generalised tonic-clonic convulsion may proceed the aforementioned manifestations in children, as in adults.

\section{Summary}

Taking the history from the patient and observers may reveal several symptoms and signs which implicate the temporal limbic system and some of these manifestations may have lateralising value as described above. Video-EEG may assist in this effort. The limbic lobe may be the receptacle of propagation from seizures originating outside the limbic system; this may occur with occipital epilepsy and orbital frontal seizures. ${ }^{9}$

\section{Differential diagnosis}

The clinical picture will usually serve to distinguish temporal lobe seizures from superficially similar but distinct entities.

The most common of these are brief attacks of daytime sleep manifested by staring and unresponsiveness to voice but responsiveness to touch. The number of children who have inadequate or abnormal sleep habits is considerable. Instead of showing epileptiform or other focal abnormalities on the EEG, spontaneous sleep may occupy an unusual percentage of the tracing.

Absence attacks are distinguished by their lack of warning, their abrupt onset and offset, the bilaterally synchronous nature of any motor phenomena, the multiple attacks per day, and the bisynchronous spike-waves on most EEGs.

Benign epilepsy of childhood with Rolandic spikes can be misdiagnosed as temporal lobe epilepsy if the buccopharyngeal manifestations are mistaken for oro-alimentary automatisms and if the Rolandic spikes are mistaken for anterior temporal ones. ${ }^{10}$ This confusion may underly the favourable prognosis of some patients with temporal lobe epilepsy of some series.

Finally, complex partial seizures with limbic manifestations may arise from occipital or orbital frontal regions as mentioned above. Preceding elementary visual symptoms may suggest propagation from an occipital source. An unusual combination of limbic and supplementary motor semiology might also be consequent to both infra-Sylvian and supra-Sylvian propagation from an occipital lobe (Blume and Wiebe, submitted). Orbital frontal seizures may be exceedingly difficult to distinguish from anterior temporal ones. Patients with intractable limbic-like symptoms and spikes that appear at inferior frontal-anterior temporal electrodes $(\mathrm{F} 7,8)$ or even mandibular notch electrodes, $(\mathrm{M} 1,2)$ yet have normal temporal neuroimaging and normal memory, should be considered as having possible orbital frontal seizure origins.

\section{Electroencephalography}

Normal or non-epileptiform EEGs may occur in infants and younger children with complex partial seizures. ${ }^{5}$ Dinner et al ${ }^{11}$ studied 30 patients with childhood onset temporal lobe epilepsy and found that none of them had interictal spikes before the age of six years. Moreover, bilateral temporal discharges appear in $1 / 4^{-}$ $1 / 3$ of patients. ${ }^{2}$

Nonetheless, an extensive literature review reveals that the principal interictal spike focus in children correlated with the epileptogenic temporal lobe in $73-100 \%$ of patients aged 15 years or less (Table 1). ${ }^{12}$ Demonstration of such discharges may

Table 1: TLE surgery candidates $<15$ years of age: Principal spike focus at epileptogenic area

\begin{tabular}{lccr}
\hline & No. Patients & Localising Spikes & $\%$ \\
Jensen \& Vaernet $^{36}$ & 12 & 12 & 100 \\
Blume \& Kaibara $^{14}$ & 21 & 16 & 76 \\
Hopkins \& Klug $^{37}$ & 11 & 8 & 73 \\
Adelson $^{38}$ & 33 & 33 & 100 \\
Grattan-Smith $^{39}$ & 39 & 14 & 92 \\
Blume $^{12}$ & 14 & & 100 \\
\hline
\end{tabular}

TLE $=$ temporal lobe epilepsy 
Table 2: TLE surgery candidates < 15 years of age: CT/MRI abnormality at epileptogenic area

\begin{tabular}{lccc}
\hline & No. Patients & CT/MRI + & $\%$ \\
Hopkins \& Klug $^{37}$ & 6 & 5 & 83 \\
Adelson $^{38}$ & 33 & 26 & 79 \\
Cascino $^{40}$ & 16 & 10 & 62 \\
Duchowny $^{21}$ & 16 & 11 & 69 \\
Grattan-Smith $^{39}$ & 53 & 40 & 76 \\
Peacock $^{41}$ & - & - & $>80$ \\
Blume $^{12}$ & 14 & 14 & 100 \\
\hline
\end{tabular}

require inferior temporal leads such as mandibular notch electrodes. These have rendered sphenoidal leads unnecessary in our hands. ${ }^{13}$ Multiple recordings may be required, including those in sleep. Multifocal spikes may occur in the majority of children with unitemporal seizures but these are more active in the epileptogenic temporal lobe in most patients. ${ }^{3,14}$ Paradoxically, ictal EEG may give localising information in fewer patients than interictal spikes. ${ }^{3,15}$

Bilaterally synchronous epileptiform discharges may occur in children with unitemporal seizures but this does not augur unfavourably for surgical effectiveness. ${ }^{3,16}$

Finally, persistent arrhythmic delta activity coincides with the epileptogenic temporal lobe in many patients and is seldom, if ever, falsely lateralising when analysed over several recordings. ${ }^{3}$

\section{Neuroimaging}

The value and necessity of magnetic resonance imaging (MRI) is indicated by the results of neuropathological examination of temporal lobectomy specimens. Mesial temporal sclerosis (MTS) is the most common finding, occurring in about half of patients; among these it appears unilaterally in $80 \%$ of cases. ${ }^{17}$ MTS may be a secondary phenomenon in that many temporal lobe specimens also demonstrate extensive congenital abnormalities such as cortical dysplasias or tumours. ${ }^{18}$ Congenital lesions, including hamartomas and cortical dysplasias, account for $15-20 \%$ of recognised lesions and are particularly common in children. Neoplasms, glial or neuronal, account for $10-15 \%$ of these. ${ }^{19}$

These lesions are often subtle, requiring high quality MRI. Moreover, they may not be apparent before six years of age. Nonetheless, several studies have shown that accurately localising neuroimaging abnormalities appeared in $62-100 \%$ of patients undergoing temporal lobe epilepsy surgery in the pediatric age group (Table 2). ${ }^{12}$ The need for high quality performance and interpretation of the MRI scan is underlined by McBride et $\mathrm{al}^{20}$ who found significant temporal abnormalities in 33 of 34 MRIs which were interpreted as normal by non-epilepsy centre neuroradiologists.

The demonstration of a focal temporal lobe structural lesion by MRI, in a child with complex partial seizures, suggests two aspects of clinical importance: 1) that most or all of the seizures will arise from that lesion, and 2) that the seizure disorder will not recede spontaneously.
Computerised tomography (CT) scanning has very seldom been helpful in this clinical setting although calcified lesions, such as cavernous angiomas, may be revealed.

\section{Invasive EEG}

The localising and lateralising value of clinical manifestations, scalp interictal and ictal EEG and carefully performed MRI together should obviate the need for invasive EEG in the vast majority of cases. Accumulation of data in each of these areas has reduced the incidence of invasive recordings from a majority in the Duchowny et al (1992) series ${ }^{21}$ to few or none in the London (1997) study. ${ }^{3}$ Nonetheless, invasive subdural recordings may identify appropriate children for temporal lobectomy in the same circumstances as it does for adults, ${ }^{22}$ (Dubeau and McLachlan, this volume).

\section{NEUROLOGICAL HISTORY AND COURSE OF ILLNESS}

Although the most common neurological antecedent has been febrile convulsions, ${ }^{23}$ the relationship with its associated pathology, MTS, remains undetermined. Nonetheless, a history of febrile convulsions suggests that MTS may be at least one of the etiologies. Maher and McLachlan ${ }^{24}$ showed that duration of a febrile convulsion was the principal feature associated with MTS. Asymmetrical manifestations of any prolonged febrile convulsion may suggest a sequela of the hemiconvulsion hemiplegia epilepsy (HHE) syndrome of Gastaut et al; ${ }^{25}$ the epileptogenic temporal lobe is almost always contralateral to such asymmetrical manifestations. Although Davies et $\mathrm{al}^{26}$ have studied the relationship between duration of epilepsy, a history of childhood febrile seizures, and MTS, these relationships remain not fully established.

Carefully selected series of temporal lobe seizures reveal that the majority begin in childhood. Rocca et al, ${ }^{27}$ studying the entire Rochester Minnesota population, found that complex partial seizures began in $72 \%$ patients before age 10 years. Fifty-six $(91 \%)$ of the 63 children with temporal lobe seizures studied by Harbord and Manson, ${ }^{4}$ had their first attacks before age 10 years.

Seizures of temporal lobe origin tend to persist. Studies by Harbord and Manson ${ }^{4}$ and Kotagal et $\mathrm{al}^{28}$ found that only 10$18 \%$ of such patients are seizure-free at follow-up. Wieser et al ${ }^{29}$ have described a silent period in childhood or early adolescence, lasting several years, in which antiepileptic medication controls both the complex partial and secondary generalised seizures. The reappearance of complex partial seizures after that time heralds a difficult-to-control seizure condition. In analysing reports of temporal lobe seizures in childhood, one should include only studies supported by temporal lobe spike discharges and those which have clearly excluded benign partial epilepsy of childhood.

The early onset and persistent nature of this epileptic condition indicates that it inhibits development of the personality. Embarrassing attacks in the presence of others lowers self-esteem. This may lead to a sense of decreased competency and independence. ${ }^{5}$ Supporting these concerns is the $24-53 \%$ incidence of significant behaviour disorders in children with temporal lobe epilepsy. ${ }^{4,28,30}$ It is not surprising, therefore, that Mizrahi et $\mathrm{al}^{31}$ found that many patients who underwent temporal lobectomy for seizures beginning in childhood had difficulty adjusting to a seizure-free life. They found that social, 
Table 3: Efficacy of TLE surgery in children and adolescents

\begin{tabular}{|c|c|c|c|c|}
\hline & No. Patients & $\mathrm{SF}$ & Improved & Total \\
\hline Davidson \& Falconer ${ }^{33}$ & 40 & $22(55)$ & $7(18)$ & $29(73)$ \\
\hline Jensen \& Vaernet ${ }^{36}$ & 12 & $9(75)$ & $1(8)$ & $10(83)$ \\
\hline Rasmussen $^{42}$ & 68 & $31(46)$ & $22(32)$ & $53(78)$ \\
\hline Meyer $^{34}$ & 50 & $39(78)$ & $5(10)$ & $44(88)$ \\
\hline Harbord \& Manson ${ }^{4}$ & 15 & $5(33)$ & ? & - \\
\hline Mizrahi $^{31}$ & 7 & $2(29)$ & $5(71)$ & $7(100)$ \\
\hline Hopkins \& Klug ${ }^{37}$ & 10 & $8(80)$ & $2(20)$ & $10(100)$ \\
\hline Adelson $^{38}$ & 33 & $23(70)$ & $3(9)$ & $26(79)$ \\
\hline Duchowny $^{21}$ & 16 & $10(62)$ & $3(19)$ & $13(81)$ \\
\hline $\mathrm{Jay}^{44}$ & 7 & $3(43)$ & $3(43)$ & $6(86)$ \\
\hline
\end{tabular}

$\mathrm{SF}=$ seizure-free; $($ ) = percentages

Sources:

1) Epilepsy Surgery, Second Edition, edited by Luders, H., Raven Press, New York, 1992, pp 669-676.

2) Epilepsy. A Comprehensive Textbook, Volumes I, II, III, edited by Engel, J. Jr., and Pedley, T.A. Lippincott-Raven Publishers, Philadelphia, New York, 1997.

3) Surgical Treatment of the Epilepsies, Second Edition, edited by Engel, J. Jr. Raven Press Ltd., New York, New York, 1993.

4) Medline from National Library of Medicine.

behavioural and educational problems occurred more frequently in patients whose surgery was delayed until adult life. They concluded that attempts should be made early in the course of temporal lobe epilepsy to determine whether the seizures were intractable, in order to expedite surgical consideration.

\section{EFFECTIVENESS OF SURGERY}

A review of temporal lobe epilepsy surgery in childhood (Table 3) reveals that $29-80 \%$ of patients were rendered seizurefree by the procedure and an additional $8-71 \%$ were improved for a total of $73-100 \%$ of patients receiving benefit. The Hospital for Sick Children's series showed effective temporal lobectomy among patients whose seizures were caused by mass lesions including tumours and vascular malformations. ${ }^{32}$ Moreover, 64$78 \%$ of children attained a beneficial social/behavioural outcome from temporal lobectomy. ${ }^{21,33,34}$ However, the cautionary note sounded above about the social and psychiatric consequences of intractable epilepsy for children must be realised. This aspect needs attention both preoperatively and postoperatively.

Significant neurosurgical complications occur rarely in general temporal lobectomy series. ${ }^{35}$ None has occurred in our experience. ${ }^{3}$ Complications will be discussed by Maroun and Girvin (this volume).

\section{COMPONENTS OF EVALUATION FOR TEMPORALLOBECTOMY}

1. A careful history from the patient and observers of the attacks is the principal and first step in establishing that episodic abnormal sensations or impaired awareness do represent seizures involving one or both temporal lobes. Video-EEG may supplement this in circumstances where historical data are ambiguous. Remember that temporal-originating seizures may manifest as non-temporal motor phenomena in infants because of spread (see above).

2. Sequential EEGs are needed to: 1) support a diagnosis of temporal lobe seizures by location of principal interictal spikes, 2) to determine on which side the spikes predominate, 3) to seek focal spikes originating in other areas such as occipital or frontal lobes, 4) to exclude the slim possibility that the attacks represent absence with atypical manifestations, and 5) exclude other possibilities among the differential diagnoses.

3. If both the clinical and EEG data indicate temporal lobe seizures, a high quality MRI scan should be performed and scrutinized for single or double temporal lobe pathology.

If the clinical, electrographic and neuroimaging data are fully or largely congruent, the site of principal epileptogenesis can be assigned with confidence. Where ambiguities persist, then videoEEG monitoring would be helpful to: 1) establish the nature of the attacks, and 2) identify the location and nature of ictal EEG discharges.

If the mechanism of epileptogenesis still remains in doubt, then invasive (subdural) recordings could be carried out after having narrowed the hypothesis for site of epileptogenesis from a minimum of two to a maximum of four regions.

Although temporal lobe seizures tend to persist, adequate control by antiepileptic medication may occur. Therefore, a trial of 1-3 antiepileptic drugs, each in monotherapy, should be 
carried out. The greater the congruency of the above-described data for site of epileptogenesis, the less are the number of antiepileptic drugs required to establish intractability as surgery can be proposed more confidenlty, and thus earlier.

\section{SOME UNRESOLVED QUESTIONS}

1. Is a trial of more than two antiepileptic drugs required before surgery in childhood when the site of epileptogenesis is determined with confidence?

2. At what mental age can a child give a reliable history of the simple partial components of temporal lobe attacks?

3. How often does video-EEG add significant data to the history and under what circumstances?

4. Are there children with ultimately proven complex partial seizures whose EEGs remain normal or non-focal?

5. Is the age at which temporal MRI abnormalities can be identified with confidence gradually lowering?

6. Will memory function shift to the right temporal lobe when left temporal lobectomy is performed in early childhood?

\section{ACKNOWLEDGEMENTS}

Maria Raffa carefully and expertly prepared the manuscript.

\section{REFERENCES}

1. Brockhaus A, Elger CE. Complex partial seizures of temporal lobe origin in children of different age groups. Epilepsia 1995; 36(12): 1173-1181.

2. Aicardi J. Epilepsies with affective-psychic manifestations and complex partial seizures. In: Aicardi J. ed. Epilepsy in Children, Second Edition. New York: Raven Press, 1994: 165-206.

3. Blume WT, Girvin JP, McLachlan RS, Gilmore BE. Effective temporal lobectomy in childhood without invasive EEG. Epilepsia 1997; 38: 164-167.

4. Harbord MG, Manson JI. Temporal lobe epilepsy in childhood: reappraisal of etiology and outcome. Pediatr Neurol 1987; 3: 263268.

5. Wyllie E, Lüders H. Complex partial seizures in children. Clinical manifestations and identification of surgical candidates. Clev Clin J Med 1989; 56 (suppl). Part 1: S43-S52.

6. Wyllie E, Chee M, Granstrom ML, et al. Temporal lobe epilepsy in early childhood. Epilepsia 1993; 34: 859-868.

7. Holmes GL. Partial complex seizures in children: an analysis of 69 seizures in 24 patients using EEG FM radiotelemetry and videotape recording. Electroenceph Clin Neurophysiol 1984; 57: 13-20.

8. Kotagal $\mathrm{P}$, Luders $\mathrm{H}$, Morris $\mathrm{HH}$, et al. Dystonic posturing in complex partial seizures of temporal lobe onset: a new lateralizing sign. Neurology 1989; 39: 196-201.

9. Blume WT, Whiting SE, Girvin JP. Epilepsy surgery in the posterior cortex. Ann Neurol 1991; 29: 638-645.

10. Aicardi J. Epilepsy in Children, Second Edition. New York: Raven Press 1994; 144.

11. Dinner DS, Luders H, Rothner AD, Erenberg G. Complex partial seizures of childhood onset: a clinical and encephalographic study. Cleve Clin Q 1984; 51: 287-291.

12. Blume WT.Temporal lobe epilepsy surgery in childhood: rationale for greater use. Can J Neurol Sci 1997; 24: 95-98.

13. Sadler RM, Goodwin J. Multiple electrodes for detecting spikes in partial complex seizures. Can J Neurol Sci 1989; 16: 326-329.

14. Blume WT, Kaibara M. Localization of epileptic foci in children. Can J Neurol Sci 1991; 18: 570-572.

15. Saint-Hilaire JM, Richer F, Turmel A, Rouleau I, Bouvier G. Relative localizing value of common tests used in the preoperative investigation of epileptic patients. Can J Neurol Sci 1991; 18: 598-600.
16. Sadler RM, Blume WT. Significance of bisynchronous spike-waves in patients with temporal lobe spikes. Epilepsia 1989; 30(2): 143146.

17. Margerison J, Corsellis JAN. Epilepsy and the temporal lobes. A clinical electroencephalographic and neuropathological study of the brain in epilepsy with particular reference to the temporal lobes. Brain 1966; 89: 499-530.

18. Shields WD, Duchowny MS, Holmes GL, et al. Surgically remediable syndromes of infancy and early childhood. In: Engel J, Jr. ed. Surgical Treatment of the Epilepsies. New York: Raven Press, 1993: 35-48.

19. Browne TR, Holmes GL. Handbook of Epilepsy, Philadelphia, New York: Lippincott-Raven Publishers 1997; 55-56.

20. McBride MC, Bronstein K, Bennet B, Berg MG. The futility of nonepilepsy centre neuroimaging in intractable temporal lobe epilepsy. Epilepsia 1996; 37: 188.

21. Duchowny M, Levin B, Jayakar P, et al. Temporal lobectomy in early childhood. Epilepsia 1992; 33(2): 298-303.

22. Blume WT, Holloway G. Correlative studies of subdural electroencephalography. Epilepsia 1997; 38: 20(Abstract)

23. Falconer MA, Serafetinides EA, Corsellis JAN. Etiology and pathogenesis of temporal lobe epilepsy. Arch Neurol 1964; 19: 353-361.

24. Maher J, McLachlan RS. Febrile convulsions: is seizure duration the most important predictor of temporal lobe epilepsy. Brain 1995; 118: 1521-1528.

25. Gastaut H, Poirier F, Payan H, et al. H.H.E. syndrome: hemiconvulsions, hemiplegia, epilepsy. Epilepsia 1960; 1: 418447.

26. Davies KG, Hermann BP, Dohan FC, Jr., et al. Relationship of hippocampal sclerosis to duration and age of onset of epilepsy, and childhood febrile seizures in temporal lobectomy patients. Epilepsy Res 1996; 24: 119-126.

27. Rocca WA, Sharbrough FW, Hauser WA, Annegers JF, Schoenberg BS. Risk factors for complex partial seizures: a population-based case-control study. Ann Neurol 1987; 21: 22-31.

28. Kotagal P, Rothner AD, Erenberg G, Cruse RP, Wyllie E. Complex partial seizures of childhood onset. A five-year follow-up study. Arch Neurol 1987; 44: 1177-1180.

29. Wieser H-G, Engel J, Jr., Williamson PD, et al. Surgically remediable temporal lobe syndromes. In: Engel J, Jr. ed. Surgical Treatment of the Epilepsies, Second Edition. New York: Raven Press, 1993: 49-63.

30. Lyndsay J, Ounsted C, Richards P. Longterm outcome in children with temporal lobe seizures: I. Social outcome and childhood factors. Dev Med Child Neurol 1979; 21: 285-298.

31. Mizrahi EM, Kellaway P, Grossman RG, et al. Anterior temporal lobectomy and medically refractory temporal lobe epilepsy of childhood. Epilepsia 1990; 31: 302-312.

32. Drake J, Hoffman HJ, Kobayashi J, Hwang P, Becker LE. Surgical management of children with temporal lobe epilepsy and mass lesions. Neurosurgery 1987; 21: 792-797.

33. Davidson S, Falconer MA. Outcome of surgery in 40 children with temporal lobe epilepsy. Lancet 1975; 1: 1260-1263.

34. Meyer FB, Marsh WR, Laws ERJ, Sharbrough FW. Temporal lobectomy in children with epilepsy. J Neurosurg 1986; 64: 371376.

35. Pilcher WH, Roberts DW, Flanigin HF, et al. Complications of epilepsy surgery. In: Engel J, Jr. ed. Surgical Treatment of the Epilepsies. Second Edition New York: Raven Press, Ltd. , 1993: 565-581.

36. Jensen I, Vaernet K. Temporal lobe epilepsy. Follow-up investigation of 74 temporal lobe resected patients. Acta Neurochir 1977; 37: 173-200.

37. Hopkins IJ, Klug GL. Temporal lobectomy for the treatment of intractable complex partial seizures of temporal lobe origin in early childhood. Dev Med Child Neurol 1991; 33: 26-31.

38. Adelson PD, Peacock WJ, Chugani HT, et al. Temporal and extended temporal resections for the treatment of intractable seizures in early childhood. Pediatr Neurosurg 1992; 18: 169178.

39. Grattan-Smith JD, Harvey AS, Desmond PM, Chow CW. 
Hippocampal sclerosis in children with intractable temporal lobe epilepsy: a clinical and MRI correlative study. Epilepsia 1993; 34: 127(Abstract)

40. Cascino GD, Jack CR, Jr., Parisi JE, et al. MRI in the presurgical evaluation of patients with frontal lobe epilepsy and children with temporal lobe epilepsy: pathologic correlation and prognostic importance. Epilepsy Res 1992; 11(1): 51-59.

41. Peacock WJ, Comair Y, Hoffman HJ, et al. Special considerations for epilepsy surgery in childhood. In: Engel J, Jr. ed. Surgical Treatment of the Epilepsies, Second Edition. New York: Raven Press, 1993: 541-547.
42. Rasmussen TB. Temporal lobe seizures in childhood: surgical aspects. In: Blaw ME, Rapin I, Kinsbourne M eds. Topics in Child Neurology. New York: Spectrum Publications, 1977: 143157.

43. Adams CBT, Beardsworth ED, Oxbury SM, Oxbury JM, Fenwick PBC. Temporal lobectomy in 44 children: outcome and neuropsychological follow-up. J Epilepsy 1990; 3 (Suppl. 1): 157-168.

44. Jay V, Becker LE, Otsubo H, et al. Pathology of temporal lobectomy for refractory seizures in children. Review of 20 cases including some unique malformative lesions. J Neurosurg 1993; 79: 53-61. 